\title{
O que é ciência? Uma análise das concepções prévias de docentes em formação inicial
}

\section{What is science? An analysis of the previous conceptions of teachers in initial training}

\author{
Laura Oestreich (lauraoestreich@ @otmail.com) \\ Universidade Federal de Santa Maria (UFSM) \\ Matheus Gutler Paim (matheuspaim61@ @otmail.com) \\ Universidade Federal de Santa Maria (UFSM) \\ Eduarda Tais Breunig (dudabreunig@hotmail.com) \\ Universidade Federal de Santa Maria (UFSM) \\ Andréa Inês Goldschmidt (andreainesgold@gmail.com) \\ Universidade Federal de Santa Maria (UFSM)
}

Resumo: O presente trabalho teve como objetivo investigar as concepções prévias sobre Ciência e as implicações do trabalho científico para a sociedade entre acadêmicos do terceiro semestre de licenciatura em Ciências Biológicas de uma universidade localizada no interior do RS. O percurso metodológico se baseou numa abordagem qualitativa, onde 36 estudantes responderam à questão "O que é Ciência?" em uma folha de papel. Esse material foi recolhido e analisado conforme a análise de conteúdo. Posteriormente, dividimos os alunos em grupos com quatro integrantes e distribuímos um envelope com 20 imagens. Desta vez, os alunos deveriam organizar um cartaz classificando as imagens que julgavam ter alguma relação com a Ciência ou não. Este material foi recolhido e analisado de forma interpretativa. Os resultados evidenciam que a maioria dos futuros professores possuem uma concepção empirista da Ciência. Além disso, as implicações diretas da atividade científica, tanto benéficas, quanto nocivas para a sociedade são percebidas. Ainda assim, as consequências sociais, como a "Fome" e o "Trabalho infantil" não foram relacionados à Ciência pelos estudantes. Ao fim, sinalizamos a importância desse tema permear os processos formativos a fim de permitir ao futuro professor desconstruir, reconstruir e/ou ampliar suas concepções sobre a Ciência.

Palavras-chave: Ensino de ciências; Formação de professores; Concepções alternativas/ingênuas.

Abstract: The present work aimed to investigate the previous conceptions about Science and the implications of scientific work for society among academics of the third semester of degree in Biological Sciences of a university located in the interior of RS. The methodological path was based on a qualitative approach, where 36 students answered the question "What is Science?" on a sheet of paper. This material was collected and analyzed according to the content analysis. Subsequently, we divided the students into groups with four members and distributed an envelope with 20 images.

Recebido em: 18/01/2021

Aceito em: 24/02/2021 
This time, the students should organize a poster classifying the images that they thought had some relation with Science or not. This material was collected and analyzed in an interpretative way. The results show that the majority of future teachers have an empiricist conception of Science. In addition, the direct implications of scientific activity, both beneficial and harmful, for society are perceived. Still, the social consequences, such as "Hunger" and "Child labor" were not related to Science by students. At the end, we signal the importance of this theme to permeate the training processes in order to allow the future teacher to deconstruct, reconstruct and / or expand his conceptions about Science.

Keywords: Science teaching; Teacher training; Alternative / naive conceptions.

\section{INTRODUÇÃO}

O conceito de Ciência tem sido construído no decorrer da história, passando por diversas transformações. Ciência, do latim scientia, significa sabedoria e/ou conhecimento. Ferreira (2009) sinaliza que a Ciência é comumente definida como um conjunto de conhecimentos socialmente produzidos, historicamente acumulados dotados de universalidade e objetividade que permitem sua transmissão; e estruturados com métodos, teorias e linguagens próprias, que visam compreender e orientar a natureza, bem como as atividades humanas.

Por outro lado, Campos (2010) compara a Ciência com lentes, as quais permitem que os sujeitos compreendam a realidade. O mesmo autor ainda adverte que todas as lentes - as diversas formas de ler o mundo - possuem distorções e diante disso, uma teoria bem aceita atualmente, pode ser substituída por outra mais próxima da realidade e cientificamente coerente.

Silva (2014) explica que a imagem pública da Ciência se volta para a neutralidade, objetividade e absolutismo da própria Ciência, facilmente traduzida em expressões como "cientificamente comprovado". Ainda segundo a autora, "estas pequenas expressões soam quase como "palavras mágicas" para a maioria da população, aspirando uma confiança cega que os isenta de qualquer outra reflexão" (p. 156). Santos e Mortimer (2001) corroboram afirmando que a Ciência é vista como uma atividade neutra, restrita a especialistas que trabalham autonomamente em busca de um conhecimento universal e desinteressado, sem responsabilidade sobre seu uso e suas consequências. 
Em seu livro “O que é Ciência, Afinal?”, Alan Chalmers traz essa questão provocativa e, após diversas reflexões sobre a Ciência, sinaliza que não há uma resposta para esta pergunta, pois não é possível "estabelecer ou defender uma caracterização tão geral da Ciência" (1993, p. 197). Este autor ainda afirma que os conhecimentos devem ser analisados de acordo com o grau de sucesso no cumprimento dos seus objetivos iniciais, bem como os métodos utilizados para alcançá-los.

Podemos perceber a existência de uma diversidade de entendimentos acerca da Ciência. Todavia, cabe estabelecer uma conexão entre as ideias de Ciência e as construções para tanto, advindas dos distintos períodos históricos. Assim, Chauí (2000) explica que existem três principais concepções de Ciência ou de ideias de cientificidade: racionalista, empirista e construtivista:

- A concepção racionalista - que se estende dos gregos até o final do século XVII afirma que a Ciência é um conhecimento racional dedutivo e demonstrativo como a matemática; portanto, capaz de provar a verdade necessária e universal de seus enunciados e resultados;

- A concepção empirista - que vai da medicina grega e Aristóteles até o final do século XIX - afirma que a Ciência é uma interpretação dos fatos baseada em observações e experimentos, os quais permitem estabelecer induções e que, ao serem completados, oferecem a definição do objeto, suas propriedades e suas leis de funcionamento; e

- A concepção construtivista - iniciada no século passado - considera a Ciência uma construção de modelos explicativos para a realidade e não uma representação da própria realidade.

Esses entendimentos acerca do que é Ciência influenciam também na prática docente. Pórlan et al. (1998) explicam que concepções racionalistas e empiristas estão mais relacionadas à concepção tradicional do processo de ensino-aprendizagem, ainda que de forma pouco evidente. Ferraz e Oliveira (2006, p. 87) acrescentam que "os professores tendem a manter, tacitamente, as mesmas concepções de Ciência que vivenciaram na universidade". Ademais, Silva (2014) adverte que o professor que possui uma prática pedagógica apoiada em concepções equivocadas, ou mesmo confusas, acerca da Ciência e da Tecnologia pode comprometer o processo de ensino e de aprendizagem da área. Portanto, estar atento e discutir acerca destas concepções já na formação inicial docente é fundamental. 
De acordo com Pozo e Crespo (2009) as concepções prévias ou alternativas são representações espontâneas da realidade, construídas a partir de aprendizagens sociais, culturais e dependentes das relações e interações de cada indivíduo. Logo, são fundamentadas em experiências vividas e, portanto, se consolidam e tornam-se altamente resistentes. É a partir dessas que o educador pode criar uma ponte entre o saber popular e o conhecimento científico (HOFFMANN; NAHIRNE; STRIEDER, 2017).

Assim, é importante investigar qual o entendimento dos futuros professores sobre a Ciência, para que, por meio dessas concepções sejam oportunizados momentos de reflexões e espaços de discussão que forneçam subsídios para os licenciandos compreenderem melhor a área e desenvolverem arguições a respeito de concepções adequadas para o aprimoramento da prática docente.

Dentro desta abordagem, a pesquisa teve como objetivo investigar as concepções prévias sobre Ciência e as implicações do trabalho científico para a sociedade entre acadêmicos do terceiro semestre de licenciatura em Ciências Biológicas de uma universidade localizada no interior do RS.

\section{PERCURSO METODOLÓGICO}

A metodologia desta pesquisa possui uma abordagem qualitativa, permitindo um olhar aprofundado dos pesquisadores para os detalhes que envolvem a temática pesquisada (MOREIRA, 2003). Bogdan e Biklen (2006) caracterizam a pesquisa qualitativa como tendo o ambiente natural como a principal fonte de dados, os quais são basicamente descritivos; tendo uma íntima relação com o pesquisador, pois ele é o principal instrumento; valorizar os processos aos resultados e perspectivas dos participantes e, por fim, analisando os dados de forma indutiva, dentro de um quadro teórico.

Os sujeitos pesquisados são discentes do terceiro semestre da licenciatura em Ciências Biológicas de uma Universidade Federal do interior do Rio Grande do Sul. Contamos com a participação de 36 alunos e esta pesquisa ocorreu no decorrer de uma aula, na disciplina de Fundamentos da Educação.

Assim, solicitamos que os alunos formassem grupos com quatro integrantes e respondessem "O que é Ciência?" em uma folha à parte. Esse material foi recolhido e analisado conforme a Análise de Conteúdo elucidada por Bardin (2011). 
Posteriormente, ainda em sequência à aula, com o intuito de compreender melhor os entendimentos dos alunos sobre Ciência, distribuímos para cada grupo um envelope contento 20 imagens, sendo oferecido o mesmo material imagético para todos os grupos. As imagens em questão são apresentadas no Quadro 1.

Quadro 1 - Imagens utilizadas para a investigação das concepções sobre Ciência.

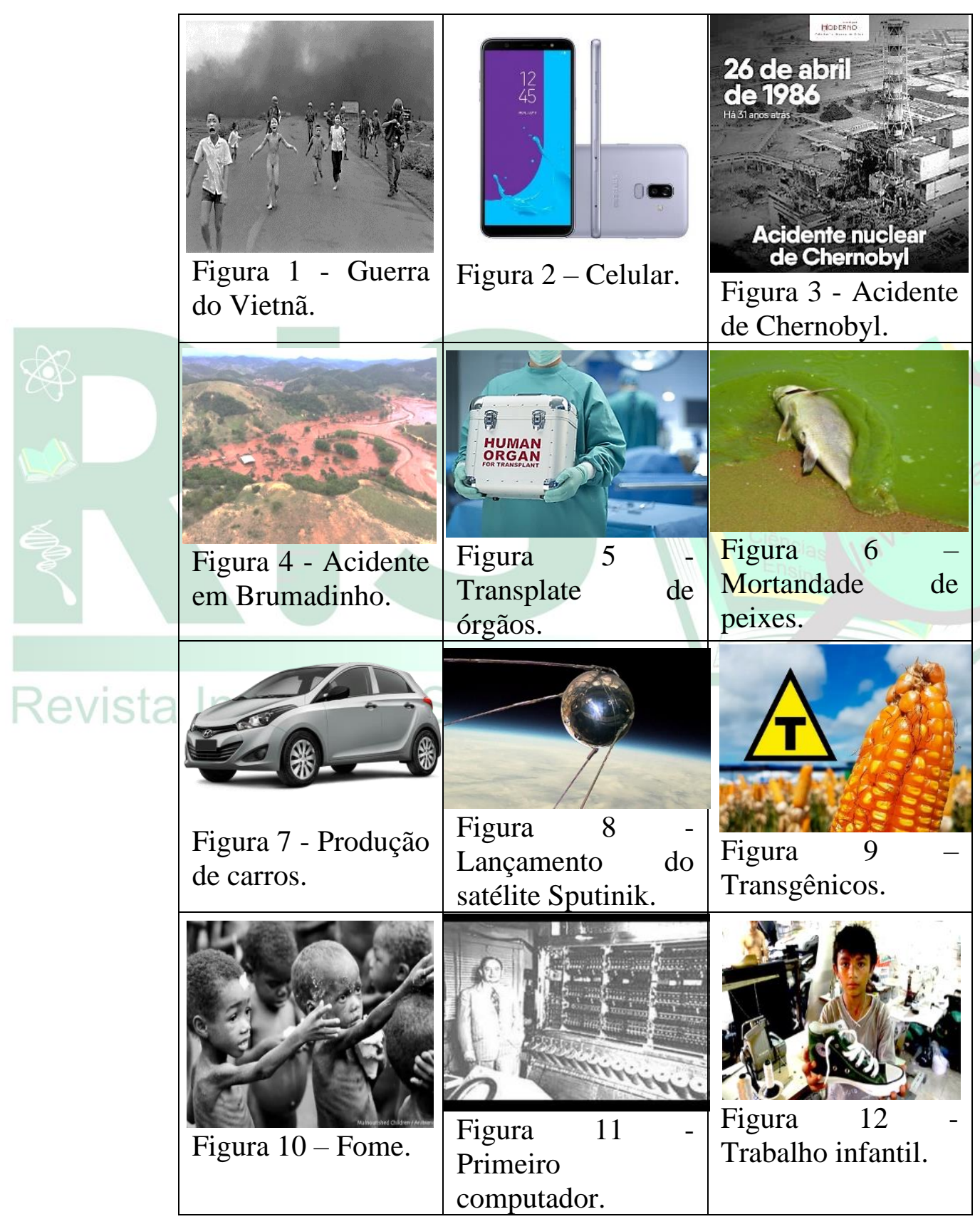




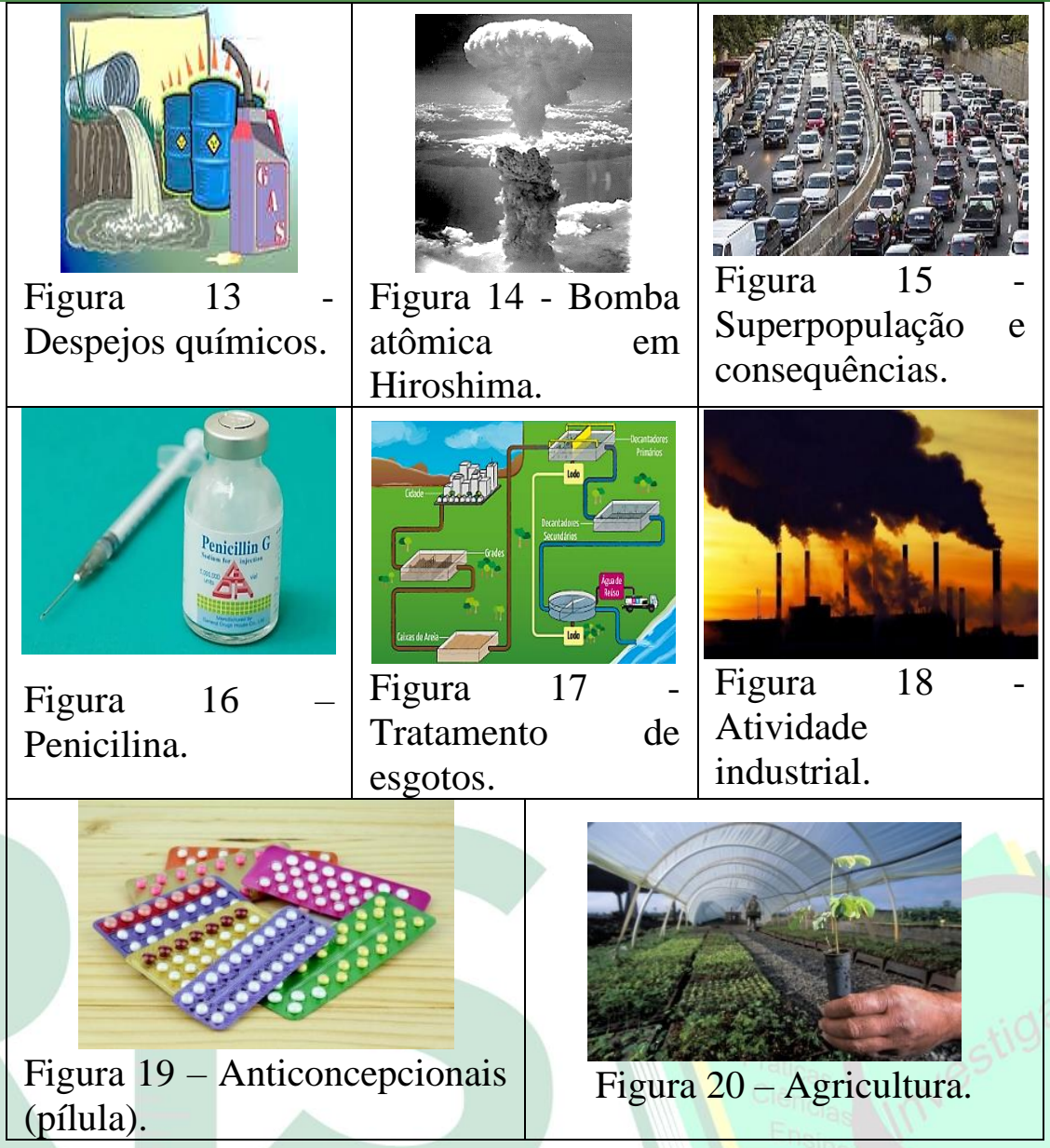

Fonte: Organizado pelos autores a partir de imagens disponíveis on-line.

Nossa opção metodológica pelo conteúdo imagético, se deu, pois, conforme Bruno (2018), as imagens são compreendidas de diferentes formas de acordo com as vivências, concepções e bagagem sociocultural dos estudantes. Assim, percebemos neste recurso uma possibilidade para nossa investigação.

Em continuidade à proposta anterior, solicitamos que cada grupo sinalizasse em um cartaz aquelas imagens que consideravam possuir alguma relação com Ciência. No término da aula, os cartazes foram recolhidos, de modo que pudessem compor o banco de dados para análises. Ao todo foram confeccionados 9 cartazes, advindos dos 9 grupos formados na atividade.

Os resultados são apresentados por meio de tabelas e quadros com as categorizações emergidas da análise. Para melhor apresentação e discussão, o tratamento dos resultados contou com as respectivas porcentagens de ocorrência de cada categoria e subcategorias, apresentadas na próxima seção. 


\section{RESULTADOS E DISCUSSÃO}

Os resultados obtidos a partir da questão "O que é Ciência", possibilitaram a organização de categorias e subcategorias de análise, como apresentado na Tabela 1. Ciência?"'

Tabela 1 - Percentuais de representação das categorias emergentes a partir da questão: “O que é

\begin{tabular}{|c|c|c|}
\hline CATEGORIAS & Subcategorias & $\%$ \\
\hline \multirow[b]{3}{*}{$\begin{array}{l}\text { Concepção } \\
\text { Construtivista }\end{array}$} & $\begin{array}{l}\text { Ciência como sinônimo de } \\
\text { conhecimento }\end{array}$ & 15,8 \\
\hline & Ciência como sinônimo de estudo & 10,5 \\
\hline & $\begin{array}{l}\text { Ciência como sinônimo de produção } \\
\text { de resultados e inovações }\end{array}$ & 5,3 \\
\hline & $\begin{array}{l}\text { Ciência para explicar os eventos do } \\
\text { cotidiano, como parte da vida }\end{array}$ & 5,3 \\
\hline & Subtotal & 36,9 \\
\hline \multirow{3}{*}{$\begin{array}{l}\text { Concepção } \\
\text { Empirista }\end{array}$} & $\begin{array}{l}\text { Ciência relacionada à pesquisa, } \\
\text { descobertas e observações para a } \\
\text { humanidade }\end{array}$ & 26,3 \\
\hline & $\begin{array}{l}\text { Ciência para observar e explicar a } \\
\text { natureza }\end{array}$ & 10,5 \\
\hline & Subtotal & 36,8 \\
\hline \multirow{4}{*}{$\begin{array}{l}\text { Concepção } \\
\text { Racionalista }\end{array}$} & $\begin{array}{l}\text { Ciência para dar respostas às } \\
\text { perguntas - razão }\end{array}$ & 10,5 \\
\hline & Ciência para comprovações - razão & 10,5 \\
\hline & \begin{tabular}{|lll} 
Ciência $\quad$ como & explicação & de \\
fenômenos & razão
\end{tabular} & 5,3 \\
\hline & Subtotal & 26,3 \\
\hline
\end{tabular}

Podemos observar que a visão que se destacou com $26,3 \%$ foi a concepção aplicada da Ciência, por vezes atrelada ao laboratório e às atividades desenvolvidas por cientistas realizando pesquisas, "descobertas" e observações que possam melhorar a vida da humanidade. Tal concepção é tão marcante, que Bernard e Crommelinck (1992) sinalizam para uma crença da Ciência, como uma convicção de progresso. Os resultados evidenciam confusões entre a Ciência, o trabalho do cientista e o próprio método científico. 
Além disso, Ferraz e Oliveira (2006) acrescentam que na concepção empirista, os estudos científicos ocorrem sem a interferência do observador, isto é, acredita-se fortemente na neutralidade do cientista. Tal ideia é fortemente criticada por Chalmers (1993) ao elucidar que o pesquisador não é neutro, mas sim dotado de perspectivas pessoais e culturais o que, consequentemente, influencia no seu trabalho.

Trata-se particularmente da Ciência como uma questão de "descobrimento" ou se reduz à prática dos processos com o esquecimento dos conteúdos. Referente ao trabalho do cientista Cachapuz et al. (2011) e Fernandez et al. (2002) corroboram afirmando que há uma forte visão individualista do trabalho do cientista; ou seja, os conhecimentos científicos são gerados unicamente por "gênios" isolados em seu ambiente de trabalho, geralmente caracterizado como o laboratório. Essa visão contribui para gerar distorções no que se refere à concepção da atividade científica, bem como a maneira em que a Ciência é produzida, disseminando uma concepção de Ciência elitista e destinada a uma pequena parcela da sociedade.

Essa imagem da Ciência e dos cientistas é totalmente fragmentada e ainda, estereotipada, sendo imprescindível desenvolver com os alunos a ideia de que a Ciência foi e é construída por cientistas que se dedicaram muito, cometeram diversas tentativas frustradas até chegar a um resultado final. Além disso, é preciso esclarecer que existem diversas pessoas envolvidas em todo o processo de construção do conhecimento; ou seja, não foi apenas um cientista que contribuiu para tais "verdades" que conhecemos hoje, e, não obstante, que essas contribuições, denominadas erroneamente como verdades, não devem ser tratadas como "imutáveis", pois isso faz com que não se construa justamente o olhar reflexivo e crítico sobre a Ciência (BREUNIG; AMARAL; GOLDSCHIMIDT, 2019).

Ainda, considerando a Ciência como sendo o resultado do acúmulo de informações geradas pela observação e experimentação, a partir da interpretação e solução de problemas, temos uma visão caracterizada como empirista. Ferraz e Oliveira (2006) sintetizam que nessa concepção é fundamental a experiência e a utilização do método científico. Logo, a subcategoria "Ciência para observar e explicar a natureza" $(10,5 \%)$ também está relacionada a esta ideia. Assim, podemos concluir que 36,8\% dos pesquisados tem uma concepção empirista da Ciência, uma ideia que conforme Chauí (2000) é proveniente ainda do século XIX. 
Alguns conceitos equivocados surgiram nas respostas, apresentando igualmente uma visão ingênua, do ponto de vista de que a Ciência racionalista $(26,3 \%)$, que tem a função de "comprovar algum fato ou fenômeno", o que denota da crença de que a Ciência comprova, torna verdadeiro, absoluto, imutável e não de que a Ciência se constrói e é dinâmica. Sobre isso, Silva (2014) adverte que a percepção geral e de senso comum - induzida por propagandas - é de que a Ciência e a Tecnologia estabelecem verdades e produzem resultados positivos para o progresso humano, sendo comum muitos confiarem nelas como se confia numa divindade.

Dentro destas ideias, as teorias científicas são vistas como sistemas formais e axiomáticos caracterizando o "aspecto de arquivo da Ciência", organizado de conhecimentos produzidos por meio de pesquisa, distribuídos em esquemas teóricos, publicados e divulgados nos meios (FONTES; SILVA, 2004). Portanto, a Ciência é um conhecimento racional dedutivo e demonstrativo, capaz de provar a verdade necessária e universal de seus enunciados e resultados, sem deixar qualquer dúvida possível.

A partir das subcategorias "Ciência para dar respostas às perguntas" (10,5\%); "Ciência para comprovações" (10,5\%) e "Ciência como explicação de fenômenos" $(5,3 \%)$, elucidam uma concepção racionalista. Essa ideia é ainda mais antiga, Conforme Chauí (2000) essa concepção é advinda do século XVII, onde a Ciência era vista como uma tentativa de explicar racionalmente os fenômenos naturais.

Aragão e Figueirôa (2013, p. 3765) sinalizam que “o racionalismo é uma interpretação de Ciência que a coloca como universal, no qual a realidade poderá ser entendida através da lógica matemática e verificada pelos experimentos”. Ferraz e Oliveira (2006, p. 88) explicam que na concepção racionalista "o pensamento impera com absoluta independência de toda a experiência”. Assim, Aragão e Figueirôa (2013) acrescentam que essa concepção compreende a Ciência como um processo dedutivo, enquanto que a concepção empirista se volta para uma Ciência que se consolida através da indução. Para além disso, acreditamos ser importante destacar que a Ciência é uma atividade humana em que se investiga o mundo para conhecê-lo melhor e ter condições de intervir nele.

Ademais surgiram algumas subcategorias que relacionaram à Ciência ao conhecimento gerado ou construído, enfocando a visão construtivista da Ciência. Nesta, o cientista combina dois procedimentos - um vindo do racionalismo e outro vindo do empirismo - e a eles acrescenta um terceiro, vindo da ideia de conhecimento 
aproximativo e corrigível. Surgiram assim, as subcategorias "Ciência como sinônimo de conhecimento" (15,8\%); "Ciência como sinônimo de estudo" (10,5\%); "Ciência como sinônimo de produção de resultados e inovações" (5,3\%); e, "Ciência para explicar os eventos do cotidiano, como parte da vida" (5,3\%), evidenciando ideias de que a Ciência irá proporcionar inovações, avançar na Tecnologia sem pensar nos processos em si. Essa ideia totalizou $36,9 \%$ de frequência para uma concepção que se aproxima das ideias construtivistas, que segundo Chauí (2000), tem início no século XX e vem, pouco a pouco, se estabelecendo dentro do espaço educacional. Cabe explicitar que:

\begin{abstract}
As ideias que permeiam a concepção construtivista estão vinculadas diretamente ao fato de se considerar a Ciência como uma forma de aproximação da realidade. Para tanto a concepção construtivista traz à tona métodos racionalistas e empiristas que, ao contrário do que os modelos ideais dessas duas concepções sugerem, não reproduzirão a realidade, mas sim uma representação dela. A ideia de verdade absoluta não faz sentido na lógica construtivista (ARAGÃO; FIGUEIRÔA, 2013, p. 3765).
\end{abstract}

Ainda assim, cabe ressaltar que em nenhuma das respostas conseguimos verificar o conceito mais amplo que temos da Ciência, onde ela não é mais entendida como a busca de domínio do mundo, mas sim como uma atividade que, por meio da aplicação de procedimentos científicos, busca compreender, explicar ou modificar a realidade existente ou observada, gerando desta forma o conhecimento científico (KRASILCHIK, 2000).

Estamos cercados de tecnologia, ela nos envolve diariamente e representa o modo de vida da sociedade, na qual a cibernética, automação, engenharia genética, computação eletrônica são alguns dos ícones da sociedade tecnológica. Por isso, a necessidade de refletir sobre a natureza da tecnologia, sua necessidade e função social se torna cada vez mais válido, pois o avanço tecnológico acelera progressivamente (SILVEIRA; BAZZO, 2009).

Em comparação ao que já se sabe acerca das concepções relacionadas à Ciência, nossos resultados possuem diversos pontos de aproximação com outros estudos relatados na literatura científica. Um artigo de revisão publicado por Harres (1999) denunciava que os professores de Ciências possuem uma visão empirista da Ciência apoiada na observação e na produção de conhecimentos por meio do método científico.

O cenário é bastante semelhante ao investigar alunos da educação básica. Em uma pesquisa com 250 alunos do ensino médio de escolas públicas, Avanzi et al. (2011) verificaram que essa ideia empirista da Ciência é presente para a maioria dos estudantes. 
Conforme os autores este fato está intimamente ligado à forma como a mídia caracteriza a Ciência.

Igualmente, ao olharmos para os professores já atuantes na educação básica, o estudo de Zamunaro, Borges e Caldeira (2003, p. 03) sinaliza que os professores se referem à Ciência como sendo "um fenômeno natural passível de observação", trazendo um viés fortemente indutivista em sua fala. Não obstante, ao investigar futuros professores de pedagogia - que serão responsáveis pelo início do processo de alfabetização científica nas crianças - Rodrigues et al. (2019) revelam que para estes licenciandos a Ciência é puramente experimental, logo estes futuros profissionais são guiados por uma concepção bastante racionalista de Ciência.

Entretanto, o fato de já possuirmos um percentual de alunos que compreende a Ciência com uma concepção mais construtivista é algo recente e possibilita a crença em um futuro onde a Ciência seja compreendida de forma mais ampla, como uma ferramenta a qual homens e mulheres buscam compreender sua realidade e transformála, por meio de procedimentos científicos, de acordo com as suas necessidades sócio históricas.

A seguir apresentamos os resultados provenientes das classificações imagéticas realizadas pelos alunos (Tabela 2). Os valores encontrados referem-se ao número de grupos que realizaram as classificações, sendo considerado a totalidade de grupos (9) para uma classificação, como $100 \%$.

As classificações realizadas pelos estudantes nos permitiram inferir que a maioria deles compreende a Ciência como uma atividade que favorece o progresso, mas também que esta pode ser nociva para a sociedade. Inferimos isso, ao observar que tanto a imagem do "Acidente em Chernobyl”, quanto a representação do "Transplante de órgãos" foram relacionadas por todos os grupos, como imagens atreladas à Ciência.

Cabe sinalizar que o "Acidente em Chernobyl” ocorreu em 1986, em um reator da usina nuclear Vladimir Lênin a qual, além de produzir energia para cidades industriais e residenciais, também fabricava bombas nucleares. Tal acontecimento, fruto de um erro humano e de problemas no projeto da usina, gerou muitas consequências para a população e o meio ambiente devido à grande quantidade de material químico lançado para a atmosfera, chegando os cálculos a uma liberação cerca de 50 ton. de produtos nucleares, outros assinalam como 3 milhões de terabecqueréis, além disso outros consideram 10 vezes mais do que a bomba de Hiroshima. A população precisou ser 
evacuada o mais rápido possível da cidade e a Organização Mundial da Saúde (OMS) aponta para um total de 59 mortes, porém esse número oscila em outras pesquisas. Esse acidente é um exemplo de como a Ciência pode trazer malefícios e prejuízos à população (SUGUIMOTO; CASTILHO, 2014) e merece ser discutido com os alunos sobre a não neutralidade da Ciência.

Tabela 2 - Associação das Imagens à Ciência, conforme percepção dos alunos em números absolutos (ABS) e percentuais.

\begin{tabular}{l|c|c|c|c}
\hline \multirow{2}{*}{\multicolumn{1}{c|}{ IMAGENS }} & \multicolumn{3}{c|}{ Foi relacionada à Ciência? } \\
\cline { 2 - 5 } & \multicolumn{2}{|c}{ Não } & \multicolumn{2}{c}{ Sim } \\
\cline { 2 - 5 } ABS & $\%$ & ABS & $\%$ \\
\hline F3: Acidente em Chernobyl & 0 & 0 & 9 & 100,0 \\
\hline F5: Transplante de órgãos & 0 & 0 & 9 & 100,0 \\
\hline $\begin{array}{l}\text { F8: Lançamento do satélite } \\
\text { Sputnik }\end{array}$ & 1 & 11,1 & 8 & 88,9 \\
\hline $\begin{array}{l}\text { F14: Bomba atômica } \text { Am } \\
\text { Hiroshima }\end{array}$ & 1 & 11,1 & 8 & 88,9 \\
\hline F16: Penicilina & 1 & 11,1 & 8 & 88,9 \\
\hline $\begin{array}{l}\text { F19: } \\
\text { (pílula) }\end{array}$ & 1 & 11,1 & 8 & 88,9 \\
\hline F13: Despejos químicos & 2 & 22,2 & 7 & 77,8 \\
\hline F20: Agricultura & 2 & 22,2 & 7 & 77,8 \\
\hline F9: Transgênicos & 3 & 33,3 & 6 & 66,7 \\
\hline F11: Primeiro computador & 3 & 33,3 & 6 & 66,7 \\
\hline F18: Atividade industrial & 3 & 33,3 & 6 & 66,7 \\
\hline F1: Guerra do Vietnã & 5 & 66,6 & 4 & 44,4 \\
\hline F4: Acidente em Brumadinho & 5 & 66,6 & 4 & 44,4 \\
\hline F6: Mortandade de peixes & 5 & 66,6 & 4 & 44,4 \\
\hline F7: Produção de carros & 5 & 66,6 & 4 & 44,4 \\
\hline & & & & \\
\hline
\end{tabular}




\begin{tabular}{l|c|c|c|c}
\hline F2: Celular & 6 & 66,7 & 3 & 33,3 \\
\hline $\begin{array}{l}\text { F15: Superpopulação } \\
\text { consequências }\end{array}$ & 6 & 66,7 & 3 & 33,3 \\
\hline F17: Tratamento de esgoto & 6 & 66,7 & 3 & 33,3 \\
\hline F10: Fome & 7 & 77,8 & 2 & 22,2 \\
\hline F12: Trabalho infantil & 7 & 77,8 & 2 & 22,2 \\
\hline
\end{tabular}

Sobre a imagem relacionada ao transplante de órgãos, a qual foi relacionada com a Ciência por todos os licenciandos, também vale ressaltar os diferentes pontos de vista a serem considerados acerca desse tema, uma vez que muitos aspectos legais e éticos devem ser levados em consideração. De acordo com Mendes et al. (2012, p. 950):

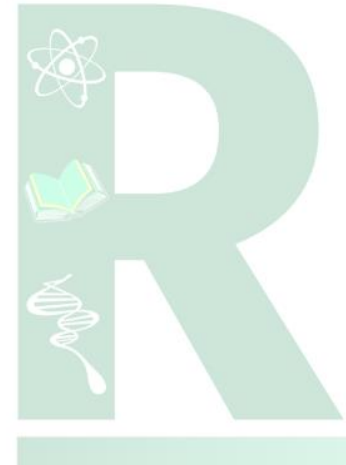

Embora a doação represente uma conduta social moralmente boa, alguns aspectos levam a acreditar que a doação ainda precisa ser incorporada à moral comum, de acordo com estudo publicado por autores brasileiros, entre eles: o descrédito no funcionamento e estrutura do sistema de saúde e da alocação de recursos, na relação de confiança entre profissional da saúde e paciente, no acesso equânime e justo, na confidencialidade doador/ receptor, no consentimento livre e esclarecido, no respeito à autonomia, na defesa da vida e no caráter inovador e recente desta modalidade de tratamento, ainda em construção. Tais fatores repercutem de modo negativo no número de doadores de órgãos disponíveis, quando se analisa a demanda de candidatos em filas de espera para transplantes.

Com isso, é perceptível que há muitos outros aspectos que devem ser trabalhados e levados em consideração quando a Ciência é aplicada na população, uma vez que fatores políticos, éticos, econômicos e sociais influenciam fortemente a aplicação da Ciência, mais uma vez mostrando a não neutralidade da mesma.

Um avanço científico-tecnológico que comumente considera somente as implicações positivas, é o desenvolvimento dos aparelhos celulares, o qual gerou um percentual de 33,3\% de relação com a Ciência. As vantagens proporcionadas pelos aparelhos são óbvias, porém malefícios podem também ser observados, como danos físicos e mentais. Souza (2018) destaca alguns destes problemas relacionados aos celulares, como malefícios de visão e audição, lesões musculares, alterações de humor, insônia, dependência e explosões.

Ao observar a lista de imagens mais relacionadas com a Ciência, se sobressaíram aquelas atreladas aos aspectos positivos da atividade científica para a humanidade como 
na imagem relacionada ao "Lançamento do satélite Sputnik", a "Penicilina" e os “Anticoncepcionais (pílulas)", atingindo percentuais de 88,9\% para cada uma.

Sem dúvida, estas imagens traçam grandes revoluções na Ciência, não tendo sido selecionadas ao acaso. A imagem que representa a penicilina merece ser ressaltada, uma vez que esta revolucionou a medicina e consiste em um dos acontecimentos mais marcantes da história da Ciência. Alexander Fleming, em 1928, foi quem iniciou os estudos com a penicilina, quando observou que suas colônias de bactérias não proliferaram devido à presença do fungo Penicillium, e com isso, a penicilina começou a ser utilizada com antibiótico. Foram muitos os benefícios desta substância; entre eles, a inovação científica, os benefícios ao nível da saúde pública e, consequentemente, os ganhos no plano da economia civilizacional (PEREIRA; PITA, 2005).

Conforme Bush (1945), a Ciência é responsável por diversos benefícios para a sociedade como colheitas mais abundantes, alimentos mais ricos, padrões de vida mais elevados, prevenção ou cura de doenças. Contudo, nem sempre os feitos científicos geram uma melhor qualidade de vida para a sociedade, visto que, ao contrário do que se acredita, a Ciência não é um processo neutro, tampouco o pesquisador possui esta característica, ainda que uma possível neutralidade seja desejável no ambiente científico (CHALMERS, 1993).

Igualmente, a "Bomba atômica em Hiroshima" também obteve este percentual elevado $(88,9 \%)$ e evidencia a nocividade que a Ciência pode assumir a fim de satisfazer determinados interesses. O fato de os estudantes perceberem a Ciência ligada também às grandes catástrofes se torna interessante à medida que contraria uma visão "salvacionista" da Ciência. Silva (2014) explica que esse entendimento se volta para a crença de que a aplicação do conhecimento científico seria a solução para os problemas da sociedade.

Entretanto as consequências da atividade científica para a sociedade ainda parecem serem pouco percebidas pelos alunos. As imagens relacionadas à Guerra do Vietnã (44,4\%), Acidente em Brumadinho (44,4\%), Mortandade de peixes $(44,4 \%)$, Tratamento de esgoto (33,3\%), Fome (22,2\%) e Trabalho infantil (22,2\%) foram pouco relacionadas a Ciência. Ao que parece este entendimento está relacionado a crença na ideia do modelo linear do progresso. Neste, o desenvolvimento científico (DC) gera desenvolvimento tecnológico (DT), este gerando o desenvolvimento econômico (DE) que determina, por sua vez, o desenvolvimento social (DS - bem-estar social). 
(AULER; DELIZOICOV, 2001). Campos (2010, p. 26) acrescenta que "este modelo linear está calcado na perspectiva da neutralidade da Ciência e Tecnologia.

Contudo, o desenvolvimento científico, por vezes, culmina na acentuação dos problemas relacionados a desigualdade social, contrariando a lógica do modelo linear do progresso. Isso porque "[...] o desenvolvimento tecnológico pode representar desenvolvimento econômico somente a um pequeno grupo. Isto favoreceria a concentração de renda nas mãos de uma minoria, o que seria antagônico à ideia de desenvolvimento social [...]" (CAMPOS, 2010, p. 27).

\begin{abstract}
Para que o desenvolvimento científico e tecnológico seja menos excludente, é necessário que se levem em conta os reais problemas da população, os riscos técnico-produtivos e a mudança social. Por isso, faz-se necessário ter uma visão interativa e contextualizada das relações entre Ciência, tecnologia, inovação e sociedade e, muito especialmente, das políticas públicas mais adequadas para se gestionarem as oportunidades e perigos que envolvem uma mudança técnica. Ou seja, a questão não é tanto se a Ciência é boa ou não, mas sim se pode melhorar e como (SILVEIRA; BAZZO, 2009, p. 686).
\end{abstract}

Logo é preciso ampliar o entendimento dos educandos para além da compreensão da Ciência como propulsora do desenvolvimento, que por vezes pode se tornar nociva, como no caso dos acidentes nucleares e da criação de bombas atômicas. Se faz necessário elucidar que a própria criação de novos componentes, sobretudo tecnológicos, influencia na sociedade, pois por vezes, são gerados a partir de condições ilegais de trabalho, como o trabalho infantil. Outro exemplo dessa mesma questão é a fome. Sobre isso Auler e Delizoicov (2006, p. 343) sinalizam:

[...] para reduzir/acabar com a carência alimentar, com a fome, efetivamente, é necessário produzir alimentos em quantidade suficiente. Nesse aspecto, a Ciência e Tecnologia podem contribuir significativamente, aproveitando-se, inclusive, os avanços da biologia molecular. Contudo, a Ciência e Tecnologia não possuem nenhum mecanismo intrínseco que garanta a distribuição dos alimentos produzidos. Ciência e Tecnologia são fundamentais no campo da produção. Porém, em termos de distribuição, há outras dimensões a serem consideradas.

Nessa perspectiva, se torna válido nos questionarmos: como a inovação tecnológica pode ser lucrativa sem causar muitos malefícios? Uma formação diferenciada dos geradores de tecnologia (engenheiros, tecnólogos), com enfoque em uma visão mais atenta a esses impactos pode suavizar os malefícios causados pela inovação tecnológica? Afinal, algum impacto sempre resultará, porém é possível minimizar a proporção dos mesmos se nos atentarmos para alguns detalhes, como a diversidade dos aspectos envolvidos, ampliando o campo de visão de todos os seres 
Edição Especial: I SSAPEC - Simpósio Sul-Americano de Pesquisa em Ensino de Ciências ISSN: 2595- $4520 \quad$ Vol. 4, n. 3. 2021

humanos, ou ainda, assumindo que o desenvolvimento de inovações tecnológicas deve ocorrer de maneira consciente e responsável, mas para isso é necessário muita prudência, tanto de quem gera a tecnologia, quanto de quem a utiliza, logo a mudança de comportamento e atitude da população em geral é crucial (SILVEIRA; BAZZO, 2009).

Neste ponto é inegável que o avanço da Ciência proporciona os mais diversos benefícios para o bem-estar do ser humano e da sociedade em diversos âmbitos, porém observando as consequências maléficas que determinados avanços científicos proporcionaram ou proporcionam, se faz necessário refletir sobre a sustentabilidade durante os processos e os impactos que cada ato da produção científica é capaz de gerar. Neste contexto, foi aproximadamente nas décadas de 1960 e 1970 que se iniciaram as discussões sobre as relações de Ciência, Tecnologia e Sociedade com questões ambientais na Educação em Ciências, em um período onde o desenvolvimento científico e tecnológico tomou discussões políticas e sociais, ocasionado pela elevação dos impactos ambientais (AULER; BAZZO, 2001).

Assim, ainda que de forma indireta, a Ciência está relacionada aos problemas de cunho social, e esta pode tanto contribuir para fortalecer desigualdades, quanto para rompê-las, sendo tal escolha dependente dos interesses daqueles que governam a sociedade. Diante disso, reiteramos que essa problemática deve estar presente nas discussões formativas docentes, a fim de evitar uma futura prática pedagógica apoiada em concepções equivocadas, e que visa a compreensão da complexidade das relações que a Ciência infere sobre a sociedade e vice-versa.

\section{CONSIDERAÇÕES FINAIS}

As concepções dos licenciandos participantes da pesquisa se voltam, principalmente, para ideias empiristas de Ciência, onde essa, é vista como uma maneira de explicar os fenômenos naturais por meio de estudos, pesquisas e "descobertas". Alguns ainda possuem concepções que se aproximam de uma ideia mais construtivista de Ciência, entretanto, poucos a entendem de forma ampla, como uma construção humana historicamente situada, dependente de contextos e interesses.

As consequências diretas, tanto positivas, quanto negativas, da atividade científica para a sociedade parecem ser percebidas pelos estudantes. Ainda assim, as 
Edição Especial: I SSAPEC - Simpósio Sul-Americano de Pesquisa em Ensino de Ciências

ISSN: 2595- $4520 \quad$ Vol. 4, n. 3. 2021

consequências sociais, isto é, àquelas relacionadas a "Fome" e ao "Trabalho infantil", por exemplo, são pouco evidenciadas como tendo relação com a Ciência.

Assim, podemos afirmar que os licenciandos ainda possuem uma visão bastante ingênua da Ciência e suas implicações para a sociedade, sendo de extrema relevância a discussão deste assunto em processos formativos, pois para ensinar Ciências é necessário que o professor tenha clareza de como funciona a construção do conhecimento científico e do que ele acarreta para a humanidade.

Por fim, como continuidade desta pesquisa, salientamos a necessidade de investigar potencialidades de propostas didáticas para abrir canais de diálogo e discussão deste tema em sala de aula com os futuros professores, a fim de desconstruir, reconstruir e/ou ampliar suas concepções sobre a Ciência.

\section{AGRADECIMENTOS}

Agradecemos à Professora Aline Cezar pela cautelosa revisão textual deste artigo.

\section{REFERÊNCIAS}

ARAGÃO, T. Z. B.; FIGUEIRÔA, S. F. M. Concepções de ciência presentes na divulgação e nas práticas de instituições não formais de ensino de ciências. In: Anais IX Congreso Internacional sobre Investigaciónen Didáctica de las Ciencias. Girona, 9-12 set, 2013.

AVANZI, M. R. et al. Concepções sobre a Ciência e os Cientistas entre Estudantes do Ensino Médio do Distrito Federal. In: Atas VIII Encontro Nacional de Pesquisa em Educação em Ciências, Campinas, SP, 5-9 dez, 2011.

AULER, D.; DELIZOICOV, D. Ciência-Tecnologia-Sociedade: relações estabelecidas por professores de ciências. Revista Electrónica de Enseñanza de las Ciencias, v. 5, $\mathrm{n}^{\circ} 2,2006$.

AULER, D.; BAZZO, A. W. Reflexões para a implementação do movimento CTS no contexto educacional brasileiro. Ciência \& Educação, v. 7, n. 1. p. 1-13, 2001.

BARDIN, L. Análise de Conteúdo. São Paulo: Edições 70, 2011.

BERNARD, F.; CROMMELINCK M. Sciences de la nature, technologies et sociétés. In: MEULDERS, M., CROMMELINCK, M., FELTZ B. Pourquoi la science? Paris: Champ Vallon, 1992.

BOGDAN, C. R.; BIKLEN, S. Investigação qualitativa em educação. Porto: Porto Editora, 2006. 
BREUNIG, E. T; AMARAL, A. S; GOLDSCHMIDT, A.I. História da ciência: revelando concepções fragmentadas a partir de imagens de cientistas. Revista Amazônia. v.15, n. 33, jan./jun. 2019. p.134-150.

BRUNO, N. V. Utilização de imagens no ensino de Ciências: concepções de professores de nível fundamental. Dissertação (Mestrado) Centro Federal de Educação Tecnológica Celso Suckow da Fonseca, 2018.

BUSH, V. [Relatório] Ciência, a fronteira sem fim. 1945.

CACHAPUZ, A.; et al. (Orgs.). A necessária renovação do ensino de ciências. São Paulo: Cortez, 2 Ed., 2011.

CAMPOS, F. R. G. Ciência, Tecnologia e Sociedade. Publicações do IF-SC, Florianópolis, SC. 2010.

CHALMERS, A. F. O que é ciência afinal? Editora Brasiliense: 1993.

CHAUÍ, M. Convite à filosofia. São Paulo: Ática, p. 320-321, 2000.

FERNANDEZ, I.; et al. Visiones deformadas de la ciencia transmitidas por la enseñanza. enseñanza de las ciencias. História y epistemología de las ciencias. v. 20, n. 3, p. 477-488, 2002.

FERRAZ, D. F.; OLIVEIRA, J. M. P. As concepções de professores de ciências e biologia sobre a natureza da ciência e sua relação com a orientação didática desses profissionais. Revista Varia Scientia, v. 06, n. 12, p. 85-106, 2006.

FERREIRA, A. B. H. Novo Dicionário Aurélio. $3^{\text {a }}$ ed. Curitiba: Positivo, 2009.

FONTES, A.; SILVA, I. R. Uma nova forma de aprender ciências: a educação em ciência/tecnologia/sociedade (CTS). Porto: Asa, 2004, 168 p.

HARRES, J. B. S. Uma revisão de pesquisas nas concepções de professores sobre a natureza da ciência e suas implicações para o ensino. Investigações em Ensino de Ciências - V4(3), pp. 197-211, 1999.

HOFFMANN, J. L.; NAHIRNE, A. P.; STRIEDER, D. M. Um diálogo sobre as concepções alternativas presentes no ensino das ciências. Arquivos do MUDI, v 21, n 03, p. 90-101, 2017.

KRASILCHIK, M. Reformas e realidade o caso do ensino das ciências. Perspectivas vol.14 no.1 São Paulo jan./mar. 2000.

MENDES, K. et al. Transplante de órgãos e tecidos: responsabilidades do enfermeiro. Texto Contexto Enferm, Florianópolis, 2012 out./dez.; 21(4): 945-53. 
MOREIRA, M. A. Pesquisa em ensino: aspectos metodológicos. Actas del PIDEC: textos de apoio do Programa Internacional de Doutorado em Ensino de Ciências da Universidade de Burgos. Porto Alegre, v. 5, p. 101-136. 2003.

PEREIRA, A.L; PITA, J.R. ALEXANDER FLEMING (1881-1955) Da descoberta da penicilina (1928) ao Prémio Nobel (1945). História: Revista da Faculdade de Letras da Universidade do Porto, III Série, vol. 6, 2005, pp. 129-15.

PORLÁN, A. R.; RIVERO, G. A.; MARTÍN, Del Pozo R. “Conocimiento profesional y epistemologia de los profesores, II: Estudios empíricos y conclusiones". Enseñanza de las Ciencias, v. 16, n. 2, p. 271-288, 1998.

POZO, J. I.; CRESPO, M. A. G. Aprendizagem e o ensino de Ciências: do conhecimento cotidiano ao conhecimento científico. 5. Ed. - Porto Alegre: Artmed, 2009.

RODRIGUES, A. V. et al. Concepções sobre ciência e fazer científico de estudantes de um curso normal e possíveis implicações nas atitudes futuras desses professores.

Alexandria: Revista de Educação em Ciência e Tecnologia, Florianópolis, v. 12, n. 2, p. 65-92, nov. 2019.

SANTOS, W. L. P.; MORTIMER, E. F. Tomada de decisão para ação social responsável no ensino de ciências. Ciência \& Educação, v. 7, n. 1, p. 95-111, 2001.

SILVA, B. H. A perspectiva CTS na formação inicial de professores de química: construindo subsídios para uma ação didático-pedagógica inovadora. 2014. 164 f. Dissertação (Programa de Pós-Graduação em Ensino das Ciências) - Universidade Federal Rural de Pernambuco, Recife.

SILVEIRA, R. M; BAZZO, W. Ciência, tecnologia e suas relações sociais: a percepção de geradores de tecnologia e suas implicações na educação tecnológica. Ciência \& educação (Bauru) vol.15, n.3 Bauru, 2009. Disponível em:

< https://www.scielo.br/pdf/ciedu/v15n3/14.pdf> Acesso em: 23 dez., 2020.

SUGUIMOTO, D. Y; CASTILHO, M. A. Chernobyl - a catástrofe. Revista da Universidade Vale do Rio Verde, Três Corações, v. 12, n. 2, p. 316-322, ago./dez. 2014.

SOUSA, A.; MIRANDA, A. Os problemas causados pelo uso excessivo de smartphones. 2018. Artigo. Disponível em: http://prpi.ifce.edu.br/nl/_lib/file/doc4147Trabalho/ARTIGO\%20terminado.pdf. Acesso em: 27 dez., 2020.

ZAMUNARO, A. N. B. R.; BORGES, J. C. F.; CALDEIRA, A. M. A. Professores e suas concepções sobre ciência e cientista: Análise semiótica. In: Atas IV Encontro Nacional de Pesquisa em Educação em Ciências, Bauru, SP, 25-29 nov., 2003. 